\title{
LOS ANTÍPODAS DE LA BUCÓLICA VI
}

This paper tries to prove the subtle relationship between the prologue and the epilogue in Virgil's Sixth Bucolic. Each of those parts -in different but complementary ways - manifest leading ideas of Virgil's poetical ideology, and the spirit of a traditional artistic conception.

La bucólica VI de Virgilio plantea un desarrollo sólo en apariencia lineal. En tanto nos dejamos llevar por la habilidad descriptiva del poeta y en tanto seguimos su propuesta, el hilo narrativo, las sutilezas lingüísticas, las historias casi yuxtapuestas en el ensamblado general del poema, las irrupciones de personajes míticos e históricos en un espacio y tiempo comunes (y en simultaneidad espiritual), los innumerables e imperceptibles detalles diseminados a lo largo de la composición, se crea en nuestro ánimo una atmósfera de tal embriaguez, que pasamos por alto, en un primer momento, la inteligente concepción y el complejo armado de la égloga. El recurso utilizado por Virgilio no era nuevo, procedía del arte alejandrino, pero el autor romano lo ha dosificado $y$ disimulado con intención evidente, según una costumbre que puede verificarse en toda su obra: una gran claridad domina la estructura compositiva de sus creaciones, pero esta apreciación constituye sólo el umbral, el primero de los accesos comprobables, la aproximación tangencial a una no ingenua trama, elaborada, sopesada y exquisitamente encordada por el arte maestro del mantuano.

Un análisis liminar de cualquiera de las composiciones virgilianas nos deja siempre la sensación de haber recorrido un camino de múltiples bifurcaciones. Sospechamos que todas ellas engrosan y acrecientan el sentido de nuestra marcha, pero en la primera travesía somos irresistiblemente llevados hacia el final por el encadenamiento sucesivo de nuevas digresiones, en apariencia distantes o, por lo menos, colaterales del motivo central. Sólo se trata, en realidad, de una propuesta distinta, elusiva, en la presentación del desarrollo temático. No obstante, a esta 
conclusión arribamos una vez que el canto ha cesado de fluir en su propia interioridad y ha comenzado a recomponerse en la nuestra.

La bucólica VI se inicia con una referencia indirecta y multívoca:

Prima Syracosio dignata est ludere uersu nostra nec erubuit siluas habitare Thalea (B. VI 1-2).

No sólo Teócrito de Siracusa - antecesor inmediato de Virgilio en el género pastoril, aunque tan distante de él en concepción y originalidad poéticas - se encuentra aludido en esos dos primeros versos y, por medio de su persona, el arte alejandrino, sino también la Magna Grecia en su conjunto, donde había florecido la escuela del maestro de Samos, cuyas enseñanzas están difundidas a lo largo de toda la creación del poeta romano: "Las doctrinas pitagóricas, sobre todo a raíz de la propaganda que les hizo el senador Nigidio Fígulo, cobraron sin cesar influencia en la alta sociedad romana, y toda la obra de Virgilio muestra hasta qué punto estaba él impregnado de ellas.» ${ }^{1}$

$\mathrm{La}$ apertura de la bucólica VI es, además, fuertemente resonante con la de la bucólica IV ${ }^{2}$, incluso en relación con el tipo de canto:

Sicelides Musae, paulo maiora canamus non omnis arbusta iuuant humilesque myricae; si canimus siluas, siluae sint consule dignae (B. IV 1-3).

Desde el inicio de las dos bucólicas se destaca, por medio de una perifrasis tomada de la simbología arborística (siluas-siluae, dupla tensiva que denota una intensificación y profundización mayores, en la escala poética, a las vibraciones alcanzadas con arbusta-myricae), la propuesta de un acrecentamiento cualitativo respecto a los temas que van a ser cantados.

Al retomar el decurso bucólico de la sexta notamos que, a continuación, se pasa a considerar la actividad del poeta. Éste acepta la sugerencia apolínea de seguir ejercitándose en un tipo de canto, acorde con su oficio pastoril. Para ello ha de postergar su incipiente dedicación al género épico. El acatamiento del consejo de Apolo le permite excusarse de

' A. M. Guillemin, Virgilio, poeta, artista y pensador, Buenos Aires 1968, pp. 74 75 ; cf. J. Carcopino, Virgile et le mystère de la quatrième églogue, París 1943, pp. 30105 y 133-155; De Pythagore aux Apótres, París 1956, pp. 36-37, 44, 71-72, 127; P. Boyance, "Le sens cosmique de Virgile", REL 32, 1954, pp. 220-249.

${ }^{2}$ La misma referencia inicial a la simbólica geografia pastoril reaparece en la bucólica $\mathrm{X}$, en triangular resonancia final, aludida bajo la invocación a Arethusa:

Extremum hunc, Arethusa, mihi concede laborem (B. X 1). 
tratar las empresas bélicas de Varo. A partir de este momento comienza a perfilarse el tema de la bucólica sexta. Se accede a la descripción de la escena y de sus personajes ${ }^{3}$ : dos pastores y una náyade (Cromis, Mnasilo y Egle, respectivamente) apresan al viejo Sileno en su antro, quien, embriagado por el vino de la víspera, duerme sin temores ${ }^{4}$. Los tres jóvenes aprovechan la ocasión para forzarlo a cantar ${ }^{5}$, antigua promesa nunca cumplida. Al despertar, advierte que lo han atado con sus propias guirnaldas; Egle le está pintando la frente y las sienes con

${ }^{3}$ B. VI 13-30.

4 «Aquí (en la bucólica VI) se trata de Sileno, dios rústico, por el cual los griegos no tenían gran respeto; lo vestian de cola, orejas de puerco y una gran panza. Virgilio lo pone en escena en medio de los accesorios habituales del tipo rocalla, gruta, guirnalda, vasos. Como de costumbre, bebió con exceso en el simposio de la víspera y helo aquí en la actitud que conviene a su estado: su cara está congestionada, las guirnaldas cayeron de su cabeza y el cántaro de la borrachera, sujeto aún por la mano, cuelga a su costado. Dos pastorcitos, Cromis y Mnasilo, lo espian; la pequeña náyade Egle los alienta. Entre los tres atan las guirnaldas como cadenas en torno de los miembros del viejo y le embadurnan la cara con jugo de moras. (...) Es visible que esta escena, que reemplaza al sainete realista habitualmente introductorio del canto de los pastores, tomó su modelo de la pintura y no de la naturaleza. La égloga VI pierde con este cambio la amenidad que ofrecen casi todas las otras, debida a la oposición de las dos partes que la componen", afirma A. M. Guillemin, op. cit., pp. 46-47. Distinta interpretación sobre la identidad del viejo Sileno ofrece G. Lieberg luego de recoger en su trabajo "L'harmonie des sphères chez Virgile?» (Bulletin de l'Association Guillaume Budé 37, 1978, pp. 343-358) las conclusiones de J. Perret acerca de la vieja divinidad (según dos grupos de textos antiguos, Sileno habita en Laconia y es el padre de Apolo arcadiano), ahonda en otras variantes de su personalidad en "Virgile et l'idée de poète créateur dans l'Antiquité" (Latomus 41, 1982, pp. 255-284); aquí se pregunta: «il faut maintenant se demander si le personnage du chanteur, de Silène, n'a pas une signification particulière. Qui fut Silène? Non seulement le compagnon toujours ivre et possédant beaucoup de traits comiques de Dionysos. Il fut aussi le chanteur inspiré, respectable et pourvu d'une sagesse profonde. (...) Virgile sera parti de cet aspect grave en caractérisant Silène dans son Églogue comme un chanteur doté d'une grande profondeur philosophique et d'une connaissance de mythes universelle. Dans ce sens va aussi le fait que Silène, chez Virgile, est forcé à révéler sa sagesse dans le carmen après avoir été enchaîné par deux bergers, Chromis et Mnasylos», pp. 274-275.

s La idea de encadenar a Sileno para obligarlo a cantar proviene de la creencia de que los dioses proféticos, poseedores de secretos de la naturaleza, no los revelaban sino tomados por sorpresa o forzados, tal como acontece con Proteo en las Geórgicas:

hic tibi, nate, prius uinclis capiendus, ut omnem expediat morbi causam euentusque secundet. nam sine ui non ulla dabit praecepta, neque illum orando flectes; uim duram et uincula capto tende; doli circum haec demum frangentur inanes.

(IV 396-400)

En el mismo canto, unos cuantos versos más abajo, Aristeo ejecuta tales preceptos (IV 437-444). 
jugo de moras. Sileno acepta el desafio sonriendo y se dispone a satisfacer el pedido de los jóvenes: subyugada y sacudida por la fuerza poderosa de su canto, la naturaleza responde de inmediato:

Tum uero in numerum faunosque ferasque uideres

ludere, tum rigidas motare cacumina quercus;

nec tantum Phoebo gaudet Parnasia rupes,

nec tactum Rhodope mirantur et Ismarus Orphea (B. VI 27-30).

El viejo Sileno despliega uno a uno diversos motivos mientras, encantados, faunos y fieras danzan, se agitan las encinas y gozan extasiados las rocas y los montes. Así se suceden, en distintos niveles de abstracción, el nacimiento del mundo, el del hombre, una breve y precisa mención al mito de Hilas, precediendo a un cuadro de profunda intensidad semántica y curioso desarrollo dramático, referido a la desafortunada Pasífae, que se ahonda con la intercalación del extravío sufrido por las Prétides, para culminar extrañamente con el adelantamiento en escena de la esposa de Minos. Sigue el mito de Atalanta y la metamorfosis de las Helíades; ambos pasajes han sido tratados de modo inusual y sorprendente. La relación entre el narrador y sus personajes alcanza un punto de extrema intimidad y conlleva una postura conceptual inquietante, insólita, según G. Lieberg, para la ideología de un mundo arraigado en el pensamiento de Parménides acerca del ser ${ }^{6}$.

Casi como contrapunto antagónico y complementario del gran cuadro dedicado a la infeliz Pasífae, Sileno se extiende luego sobre la consagración del poeta elegíaco G. Cornelio Galo, nuevo sucesor de Hesíodo en el arte de encantar con la música. La reaparición de la forma indirecta en la narración (marcada por $u t$ y las acciones verbales en pasado: duxerit, adsurrexerit, dixerit) distiende el tono de la escena y señala un reflujo hacia los momentos iniciales del canto, cuyo ejercicio pasará, lenta e imperceptiblemente, de la voz de Sileno a la de Títiro (quid loquar). Dos historias mítico-metamórficas (la Escila, Tereo y Filomela) cierran el gran fresco musical. Pero la bucólica concluye con una cosa que nos obliga a reconsiderar y recrear el sentido de toda su estructura. Es el único de los diez poemas que componen el corpus bucólico con un final tan inesperado y desconcertante: en esos cinco últimos versos de sentido denso y recapitulativo se nombra y revela al hasta entonces insospechado autor del canto escuchado. Lo que creíamos

6 G. Lieberg, en su trabajo citado "Virgile et l'idée de poète créateur dans l'Antiquité", estudia en detalle el pasaje y destaca la perspectiva sin precedentes que adopta Virgilio en su tratamiento (pp. 270-272). 
hasta este momento obra de Sileno no es sino la recreación del canto de Apolo a orillas del río Eurotas, cuyo eco intemporal congrega a una naturaleza que, extasiada aún por la resonancia del ejercicio apolíneo, enmarca el canto y cierra el poema.

Hemos intentado resumir en pocas palabras los distintos pasajes que componen la bucólica VI. El resultado ha sido, a todas luces, magro y decepcionante. La estructura compositiva de la bucólica se ha rebelado y resistido con creciente intensidad ante nuestro esfuerzo por aproximarnos a ella y abordarla por medio de un análisis lineal. Tampoco entendemos demasiado esa sucesión aparentemente indiscriminada de disimiles episodios que reúne temas como el del origen del mundo de acuerdo con la física epicúrea, en tanto el del hombre está presentado según una perspectiva mítica. Menos satisfechos y en mayor incomodidad nos dejan las incursiones, a la manera alejandrina, por diferentes y tan distantes historias míticas, o las incomprensibles inversiones del orden cronológico de los mitos ${ }^{7}$. Tenemos la sensación de que toda la bucólica VI constituye un enorme excursus y que Virgilio ha concedido especial atención - hasta el límite de descuidar la coherencia semántica - a este recurso habitual del arte alejandrino. Empero, los cinco últimos versos acrecientan nuestra perplejidad. Hasta entonces suponíamos que habíamos asistido a un relato sobre el viejo Sileno forzado por tres jóvenes a cantar, y luego, que habíamos escuchado el desarrollo de su canto. Al concluir la bucólica sabemos que el autor de dicho canto no es otro que Apolo. En medio de este juego exquisito de luces y sombras, de falsos pasadizos que reconducen a la línea de partida, Virgilio ha dispuesto con habilidad los elementos constitutivos de la pieza. Unos han sido iluminados y destacados con la intención de oscurecer y ocultar otros, pero, a su vez, cada uno de ellos ha sido seleccionado de entre una enorme gama de posibilidades $y$, de entre las variadas vertientes que ofrecen en su despliegue argumental, sólo ciertos episodios o detalles definidos y útiles al plan de la obra. Del análisis minucioso de los mitos mencionados surge, si no la comprobación efectiva, al menos la sospecha de que todos ellos han sido incluidos en el canto de Sileno a causa de su relación semántica con el significado de la bucólica, al que concurren elusivamente por un aspecto de su historia. La aparente falta de unidad y de coordinación, la disposición yuxtapuesta, casi aluvional y caótica, producen una impresión liminar de desaliño, hacen pensar en

7 Ya los antiguos escoliastas hacian notar la alteración realizada por Virgilio al describir los reinos de Saturno, el diluvio y la pareja humana, el robo y castigo de Prometeo (B. VI 41-42). 
inexperiencia e inmadurez artística, decepcionan en un primer momento la expectativa inicial, desaniman, y disgregan finalmente la atención y el interés, extraviados en un laberinto de nombres e historias que se suceden sin orden y sin coherencia. Es el momento de detenerse y, haciendo a un lado nuestra insatisfacción y disgusto por tan cambiante itinerario, tener en cuenta que el poeta no actúa como el filósofo. Su pensamiento no es teórico, no es discursivo, sino sintético, instantáneo, mítico. No estamos frente a un discurso explicativo, a la manera de Lucrecio. $\mathrm{Ni}$ tampoco estaba Virgilio en la encrucijada lingüistica del autor de De rerum natura, forjador de una lengua poética en la que pudiera expresarse una cosmovisión. La bucólica VI recuerda con intenso aliento al recreador del epicureísmo en Roma, pero marca también divergencias que irán ahondándose con el correr de los años. Los movimientos estructurales del canto de Sileno son un eco de los del proemio de la obra de Lucrecio: una onda cuya oscilación transita desde lo abstracto a lo concreto, de lo homogéneo a lo heterogéneo, para refluir finalmente a una nueva densidad conceptual ${ }^{8}$. También es desorientador, en un principio, el decurso temporal en que se inscribe el canto; del pasado inicial (namque canebat, v. 31) deambula por sucesivos y no ingenuos estadios hasta culminar en un presente final (ille canit, v. 84), ahistórico, que produce como efecto una sensación de ininterrumpida continuidad, desplegándose inmutable e incesante dentro y sobre sí misma. Los distintos momentos que conforman el gran fresco musical se abstraen paulatinamente tras un gradual movimiento temporal y un lento desplazamiento en la óptica de la tercera persona. Cada uno de los pasajes que componen y estructuran el canto de Sileno se vincula de un modo particular con la voz de su recreador: para describir el origen del mundo, la reunión de los átomos a través del vacío $\mathrm{y}$, a partir de éstos, la aparición de las tierras, los mares, el sol, las nubes, la vegetación y los animales, un verbo en tiempo pasado y un vínculo indirecto (canebat uti..., v. 31). La acción del canto se sitúa en tiempo pretérito; la intervención de Sileno se limita a recordar, a través de ese canto, cómo se había originado el mundo, desde un pasado remotísimo, auroral, hasta un presente próximo al de la historia. En cuanto al hombre, los reinos de Saturno, el robo de Prometeo y su castigo, la perspectiva temporal y el nexo con la voz del cantante han variado: refert, v. 42 y adiungit, v. 43 nos colocan en una acción presente; los mitos rememorados se tornan más vívidos, pero las acepciones propias de los verbos mantienen la objetividad se-

${ }^{8}$ Hemos expuesto estas consideraciones en: «Sobre el proemio del canto primero de de rerum naturas, Argos 4, 1980, pp. 45-62. Para una elucidación profunda del tema remitimos al estudio del Dr. C. Disandro La poesía de Lucrecio, La Plata 1950. 
mántica y la distancia entre el narrador y lo narrado 9 . Esta situación se quiebra en los pasajes siguientes: Pasiphaen solatur, v. 46; canit $\mathrm{He}$ speridum puellam, v. 61; Phaetontiadas circumdat... proceras erigit alnus, vv. 62-63, configuran la irrupción de una tercera persona subjetiva, directa, interviniente en una acción presente. En los versos citados asistimos a una curvatura de extrema tensión semántica, encubierta bajo una creciente y generalizada abstracción espaciotemporal y una paulatina intromisión del ejecutante del canto en la interioridad del mismo. El mito ya no es rememorado a través del canto de Sileno. Ahora, mito y canto se funden, acaecen en el mismo presente en que Sileno consuela a Pasífae, a lo largo de un cuadro de gran desarrollo, y la mítica reina se adelanta a escena, corporizándose ${ }^{10}$; acaece en una species donde el

${ }^{9} \mathrm{El}$ adverbio hinc, v. 41, marca un doble límite significativo. Por un lado, entre la creación del mundo (pasible de ser explicado según la teoría del epicureísmo) y la aparición del hombre (sólo comprensible a través del mito). Por el otro, entre las acciones temporales y el cambio semántico producido por la introducción de un nuevo verbo.

${ }_{10}$ Cf. vv. 55-60: claudite, nymphae... Podría admitirse la introducción de Pasífae a partir del verso 47: a! uirgo infelix, quae te dementia cepit? Para ello es necesario reconsiderar toda la escena, aceptando que Virgilio ha desdoblado el parlamento de la esposa de Minos de acuerdo con su actitud emocional: en un primer momento, la reina se lamenta de su extravío con objetiva mirada, luego refluye sobre sí misma y toma resueltamente la palabra para dirigirse a las ninfas. Nos adherimos a la posición de Luis Vives, quien propone se acepten puestos en boca de Pasífae los versos señalados (47-60), íntegros, teniendo en cuenta dos momentos que se suceden gradualmente: vv. 47-55, en tercera persona, donde encontramos a la mujer de Minos en una contemplación objetiva de sí misma y de sus actos. Tal desdoblamiento se verifica en otros momentos de la obra de Virgilio, cf. B. II 69; a! Corydon, Corydon, quae te dementia cepit!, y particularmente, en el canto cuarto de la Eneida, cuando Dido, sacudida y alterada por su pasión, rememora (como aquí Pasífae) los sucesos de un pasado reciente, conviriténdose en interlocutora de su monólogo:

Quid loquor aut ubi sum? quae mentem insania mutat, infelix Dido? nunc te facta impia tangunt?

Tum decuit, cum sceptra dabas...

(IV 596-598)

Similar problema se plantea en otra escena del canto cuarto, aunque su elaboración alcanza mayor complejidad, pues Eneas se encuentra presente mientras Dido reflexiona consigo misma como si estuviera sola:

num fletu ingemuit nostro? num lumina flexit?

num lacrimas uictus dedit aut miseratus amantem est?

(IV 369-370)

La bipartición del personaje finaliza cuando el doble refluye sobre sí mismo para retornar a la unidad personal de la que había partido. En la bucólica VI tal segmento se encuentra en los versos 55-60, a partir de claudite, nymphae... La mayor parte de los editores considera, por el contrario, que Pasífae se adelanta a escena al final del verso 55. Tal postura produce, creemos, un corte abrupto, inesperado y, en cierto modo, ilógico, en la continuidad del contexto, en particular si pensamos, de 
vate tiene la fuerza suficiente y necesaria para crear la verdadera realidad con su palabra poética ".

A continuación nos encontramos con un pasaje dedicado a Galo, poeta elegíaco por quien Virgilio sentía un profundo afecto. En este segundo gran cuadro del canto de Sileno se aprecia el retorno a las formas narrativas indirectas. Es evidente el contraste entre la presentación del mito de Atalanta (tum canit Hesperidum miratam mala puellam, v. 61) y la descripción de la historia de Galo (vv. 64-73):

\footnotetext{
Tum canit errantem Permessi ad flumina Gallum

Aonas in montis ut duxerit una sororum, utque uiro Phoebi chorus adsurrexerit omnis;

ut Linus haec illi diuino carmine pastor

floribus atque apio crines ornatus amaro

dixerit... (B. VI 64-69).
}

El verbo utilizado ha sido el mismo, canit; difiere la relación con su predicado.

El último tramo, con los mitos metamórficos de Escila y de Filomela, nos reintegra a una acción y a un contexto espaciotemporal coincidentes con los del inicio. La escena se desdobla nuevamente y reaparece plena la voz del narrador objetivo, el mismo que anunciaba el comienzo del canto de Sileno (simul incipit ipse, v. 26) apenas acababa de prometerlo, el mismo que nos transmitía la respuesta de la naturaleza, hechizada por el canto, cuando aún no habiamos empezado a escucharlo, el mismo que lo introducía y convertía en tema de su relato (namque canebat). $\mathrm{Y}$ es él mismo quien enlaza y funde su narración del canto con el canto de Sileno, cuyo origen se debe a un ejercicio preliminar de música realizado por Apolo a orillas del río Eurotas (vv. 82-86). El conjunto se asemeja a un cuadro de regresión infinita.

Hemos asistido al desarrollo de doce episodios de desigual duración, intensidad y tratamiento. Algunos de ellos han sido destacados, otros han obtenido una mención fugaz en un hemistiquio. Sea como fuere, no puede dejar de repararse en el número de pasajes incluidos en el canto

acuerdo con un sustrato semántico profundo, que se trata de una reposición viva del personaje mítico, en un paréntesis de la realidad ordinaria entreabierta por la fuerza peculiar del canto. Desde esta perspectiva, creemos que la intención de Virgilio ha sido la de reponer el mito a partir del personaje en su gradual recreación, como una realidad viviente y revelada que participa de la totalidad significativa de la bucólica VI y del corpus bucólico, apuntando a uno de los temas más caros al mantuano: el amor y su incidencia en el destino humano.

"A propósito del controvertido pasaje de Atalanta y las Helíades, véase el estudio de $\mathbf{G}$. Lieberg citado en nota 6 . 
de Sileno. Para un autor como Virgilio, tan probadamente consustanciado con una tradición poética que no conocía separación ni enfrentamiento con la ciencia, el número y el signo geométrico, paradigmas anteriores a la creación según el pensamiento pitagórico, fueron componentes naturales de su actividad artística. El comentario de Donato (4748), entre los antiguos: inter cetera studia medicinae quoque ac maxime mathematicae operam dedit, y su contemporánea repercusión en el incitante trabajo de P. Maury ${ }^{12}$, confirman no sólo una de las aficiones más íntimas de Virgilio sino, en particular, su presencia subterránea pero indeleble en el pensamiento que gobierna la totalidad de su obra ${ }^{13}$.

No seguiremos acumulando ejemplos para demostrar las dificultades de intelección que plantea la bucólica VI; creemos que los citados constituyen una muestra suficiente de la singular complejidad de su estructura compositiva. A. Tovar la califica como la pieza más brillante de todas las virgilianas y agrega: «Los temas de la poesía alejandrina, lo mismo en la dirección didáctica que en la mitología, obtienen un desarrollo amplio y erudito, a gusto de la tendencia artística en que Virgilio se mueve.» ${ }^{14}$ Esta valoración es nueva; probablemente la bucólica VI ha sido, a lo largo de los siglos, la que menos entusiasmo y mayores prevenciones despertó entre los críticos de la obra virgiliana. Así lo reconoce E. Paratore: "Una delle più belle ecloghe di Virgilio, la sesta, per lungo tempo (e anche oggi da parte di alcuni critici) è stata conside-

12 "Le Sécret de Virgile et l'Architecture des Bucoliques», Lettres d'Humanité 3, 1944, pp. 71-147, en particular p. 109 ss.

13 «Et par example, il est hors de doute que la mystique églogue à Pollion est construite sur le Septénaire», P. Maury, "Le Secret...», p. 110. La base septenaria de la bucólica IV había sido puesta de manifiesto por A. Trendelenburg (Virgilis Erlöserlied, Berlín 1926), considerándola en conjunto un Nomo apolíneo. Esa «metafisica" del número subyace a lo largo de las restantes piezas del corpus bucólico, en estrecha correspondencia con los postulados pitagóricos. Una de las menciones más controvertidas se encuentra en la bucólica VIII 75: numero deus inpare gaudet, afirmación realizada en una pieza de número par y en medio de una exaltación del ternario, primer número impar según los pitagóricos. Un orden numérico basado en la péntada domina los dos grandes cantos de la bucólica V. Por fin, si aceptamos las correcciones de Maury en cuanto al número de versos de las bucólicas III, VI y VII, obtenemos una diferencia de trece versos entre la $\mathrm{V}$ y la $\mathrm{X}$; tomadas respectivamente como cenit y nadir del corpus, notamos una diferencia númerica constante entre los dobletes de una progresión antagónica de ascenso y descenso. Asi, cuatro versos son toda la separación cuantitativa entre I y VI, entre II y VII, entre III y VIII, entre IV y IX. A su vez, esos dos números: 13 y 4 , son el fundamento de la inscripción de un decágono en una circunferencia que, con un diámetro de 13 (sea cual fuere la unidad de longitud que se adopte), contiene diez lados exactos de 4 cada uno.

14 Eglogas, Madrid 1951, p. 84. 
rata con una certa prevenzione per la difficoltà d'intenderne la struttura, di scoprire una coerenza nelle parti che la compongono." ${ }^{15}$

De entre los variados intentos críticos y atinadas observaciones que pudieren hacerse con respecto a sus múltiples problemas de interpretación, nos interesa destacar la relación substante que une dos pasajes de la sexta, aparentemente lejanos y desvinculados entre sí. Según nuestro entender, en ambos y de modo diferente se oculta el sello que determina y desde el cual fluye la ideología poética de Virgilio.

La bucólica se inicia con una poco usual introducción de doce versos, cuyos motivos no parecen relacionarse demasiado con el desarrollo posterior. La referencia a la situación personal de Virgilio nos resulta llamativa y alerta nuestra atención. El hecho de que las reflexiones personales del poeta irrumpan en el prólogo de la pieza es infrecuente; por ello mismo adquiere una valoración y significado relevantes. Según creemos, esta observación, referida a su propia condición de poeta, pone de manifiesto un momento espiritual muy importante de su vida, en el que subyace la asunción de una postura con respecto a su actividad literaria:

Cum canerem reges et proelia, Cynthius aurem uellit et admonuit: "pastorem, Tityre, pinguis pascere oportet ouis, deductum dicere carmen" (B. VI 3-5).

Nuestra atención se ha detenido, además, en los últimos cinco versos de la bucólica:
Omnia quae Phoebo quondam meditante beatus audiit Eurotas iussitque ediscere lauros, ille canit - pulsae referunt ad sidera ualles-, cogere donec ouis stabulis numerumque referre iussit et inuito processit Vesper Olympo (B. VI 82-86).

Ambos pasajes presentan una vinculación sutil pero decisiva en cuanto al arte de la composición y son el resultado de la mentalidad y perspectiva poéticas de Virigilio.

Dentro de la introducción (vv. 1-12) los cinco versos iniciales podrían considerarse como una reflexión personal tendente a delimitar y precisar la altura, alcance e intensidad de la bucólica VI. El primer segmento (vv. 1-2) señala con claridad el propósito de mantener elevada la

is "Struttura, ideologia e poesia nell'ecloga VI di Virgilio", Hommages d J. Bayet, Latomus 70, 1964, p. 509. 
palabra y anticipa la importancia que, a continuación, le asigna Apolo al canto pastoril. A partir del breve proemio de la cuarta hemos aprendido a valorar con sumo cuidado las referencias provenientes de la simbología arborística en cuanto al nivel significativo de la materia poética. Allí se oponian myricae y siluae, en obvia alusión al grado de profundidad implícito en el canto y desarrollando el enunciado conceptual maiora canamus. Alli también se establecía un sólido vínculo con la musa siciliana y, consecuentemente, con la poesía pastoril (Sicelides Musae), como declaración liminar de pertenencia a un género, aunque acotado de inmediato por la dupla complementaria maiora-siluae, que señala un incremento sensible del desenvolvimiento poético a partir del sustrato bucólico ${ }^{16}$. Aquí reaparece idéntica actitud, elaborada sobre la figura de Talia como primitiva musa campestre, inventora de la agricultura (hecho que señala la preocupación de Virgilio por retroceder y recuperar el pasado originario). La deliberada elección de esa musa fundamenta, precisa y sella, desde el primer verso, el decurso sustancial e intimo de la sexta y su inserción cualitativa en el contexto general del corpus bucólico. Talía remite, por la raíz griega de su nombre, a una idea de fecundidad y crecimiento. Por consiguiente, el tipo de indagación al que hemos de asistir está sugerido por la elusiva síntesis implícita en su nombre y se relaciona con el pasado más remoto que se pueda rescatar desde la época del poeta ${ }^{17}$. La mención de Apolo a través de su lugar de nacimiento (el monte Cintio, en la isla de Delos) responde a la misma intención. Este movimiento hacia atrás no consiste en dejar de lado el mundo helenístico; por el contrario, conlleva el esfuerzo por reinsertarlo en una totalidad de sentido que se origina y encierra en el mundo griego arcaico. Ya no se trata, como en la cuarta, de una revelación que incide sobre el futuro del mundo ni, como en la quinta, de una revelación escatológica; en la sexta, la incursión se centra en los fundamentos mismos del cosmos, en la inasible peculiaridad del hombre y su distinción genérica en forma y significado.

El segundo segmento (vv. 3-5) ahonda el tono subjetivo del proemio y profundiza la preocupación personal del poeta con respecto al alcance y la medida de su trabajo. Virgilio no recurre a rodeos o perifrasis suti-

16 Las dos bucólicas triangulan con la $\mathrm{X}$ en los mismos términos, aunque conviene destacar que sus diferencias en contenido y finalidad son evidentes. No obstante, Arethusa $(\mathrm{X} 1)$, siluae $(\mathrm{X} 8)$ responden a similares significados.

17 Sin mengua de lo afirmado y como segunda perspectiva, la referencia al ámbito pastoril en que habita Talía concuerda y refuerza las palabras que Apolo dirige a Títiro sobre el tema; de ellas se deduce que el oficio asumido por el hombre y su ejercicio deben consonar. 
les y exquisitas para describir su situación espiritual; por el contrario, se coloca como sujeto de la acción y asume una teoría del arte concebida en intima relación con el grado de madurez cognoscitiva alcanzado. En este punto debemos detenernos por un instante. Si bien es cierto que nuestro esfuerzo está encaminado a revisar la bucólica VI desde la perspectiva de las ideas rectoras del arte de Virgilio y, en particular, a formular algunas precisiones sobre el tema valiéndonos de aquellos pasajes en que tal idiosincrasia se hace más evidente, en ningún momento debemos perder de vista que la pieza es parte de un todo, y por ello encuentra su sentido pleno en la unidad conformada por los diez cantos del corpus bucólico. Las resonancias, las analogías atestiguadas entre la cuarta, sexta y décima, apenas iniciada la revisión del proemio, constituyen una ínfima proporción si se las coteja con los múltiples ejemplos del mismo tipo que atraviesan y tensan la estructura general de la obra. Dicha observación nos permite transgredir los límites propuestos de nuestro objeto de análisis para señalar la estrecha relación existente entre el Títiro de la bucólica primera y este de la sexta. Ambos se encuentran definidos con clara precisión por un hexámetro de idéntico significado (en la primera, a través de las palabras de Melibeo; en la sexta, por sí mismo); en ambos casos el verbo utilizado, meditari, se diferencia con nitidez de los usualmente empleados por Virgilio para caracterizar la actividad poética de sus pastores (ludere, canere, dicere musam, dicere uersus, dicere carmina). Meditari nos pone en contacto con un mundo de interioridad espiritual en su aspecto más profundo y reservado, donde descansa la justa medida de las cosas. Su aspecto iterativo intensifica el alcance de un ejercicio de aproximación gradual, de una progresión ininterrumpida a los dominios del espíritu:

Siluestrem tenui musam meditaris auena (B. I 2).

Agrestem tenui meditabor harundine musam (B. VI 8).

En el primer hexámetro una tensión rítmica de prieto aliento parece consonar con la gravedad semántica de la bucólica; una onda más amplia y distendida caracteriza al segundo, consecuente con la curvatura de la extensa materia poética por la que incursiona la sexta. Los dos momentos cuentan al pastor Títiro como guia; los dos pasajes, previos al desarrollo del canto, parecen exceder el marco de sus respectivas bucólicas para constituirse en anticipos simbólicos bajo cuya sombra desplegarán un movimiento ascendente (coronado en la transfiguración de Dafnis) y otro descendente (consumado en el desventurado destino de 
Galo); un díptico antagónico y complementario sobre el que se asienta la arquitectura interna del monobiblos bucólico ${ }^{18}$.

La mismidad del pastor Títiro no sólo queda confirmada por esta analogía semántica de los hexámetros citados, sino también por el diferente papel que asumen en cada una de las dos piezas, en tanto y en cuanto aceptemos que el corpus bucólico posee una unidad de significado y propone un camino de iniciación paulatina en estadios superiores del ser a través de una revelación escatológica. Con una progresión como la señalada no será incoherente encontrar a los agonistas modificados y transformados según su ubicación en los distintos niveles de la obra. Cada uno de los dos grandes hemistiquios del monobiblos bucólico se abre bajo la «meditación» de Títiro, ejecutante de un arte complejo y singular:

\author{
Tu, Tityre, lentus in umbra \\ formosam resonare doces Amaryllida siluas (B. I 4-5). \\ Non iniussa cano. Si quis tamen haec quoque, si quis \\ captus amores leget, te nostrae, Vare, myricae, \\ te nemus omne canet... (B. VI 9-11).
}

La extrema concentración semántica del resonare doces será el reparo bajo cuya sombra ha de desplegarse el díptico bucólico con todas sus connotaciones filosóficas y teológicas. En el non iniussa cano se encubre la aceptación de una verdad revelada por la potencia asuntiva y transfiguradora del canto. El rumbo lírico de la sexta se inicia con una construcción encadenada que fluye a lo largo de la introducción hasta concluir en un haec de valor recapitulativo. Desde él se reordena, en sentido inverso, el significativo horizonte latente tras las líneas que vincula haec, iniussa, deductum dicere carmen, cuyo cumplimiento alcanzará su resonancia primera en nostrae myricae, como natural respuesta a un primer esfuerzo intelectivo (leget), pero culminará en un estadio superior, omne nemus, en tanto el sustrato tensional del tal esfuerzo se encuentre sometido al cautiverio de una fuerza (captus amore) que lo impulse a sobrepasar las pruebas iniciales ${ }^{19}$.

18 Cf. C. Disandro: "Tres niveles del hombre en Virgilio", en Actas del Primer Simposio Nacional de Estudios Clásicos, Mendoza 1970, pp. 124-126.

19 Nuestro análisis se debe a que creemos advertir en el pasaje citado una construcción paralela: si quis tamen haec quoque (leget), te nostrae myricae (canent), si quis captus amore leget (haec), te nemus omne canet.

Desechamos pensar en una aclaración o intensificación lineal de una sola prótasis, así como de una sola apódosis. 
Teniendo en cuenta el contexto de las cinco bucólicas precedentes, el tan peculiar y amplio proemio de la sexta parece desbordar su propio marco de referencia para extenderse al segundo tramo de la obra. Los cantos épicos no han sobrevenido en tiempo apropiado. El pastor debe completar su ejercicio pastoril atendiendo a la advertencia de su maestro en el arte poética (Cynthius aurem uellit et admonuit...). El poeta acepta de inmediato (nunc ego) y, a la vez que abandona su intención de dedicarse a la épica, vuelve a inscribirse en la línea compositiva anunciada en la introducción de la bucólica primera, rememorando sus votos pastoriles: agrestem tenui meditabor harundine musam.

Casi insensiblemente hemos asistido a una declaración espiritual de Virgilio vinculada a su ideología poética. Su confesión, referida a una actividad paralela en el campo de la épica (cuya frecuentación parece haberse iniciado no hace mucho tiempo), su decisión de retornar al fundamento principal de los poemas bucólicos, dejando en suspenso su interés por los tristia bella (sean cuales fueren), las disquisiciones sobre la raíz originaria de su canto y sobre las posibles resonancias que pudiere alcanzar, han distraido y desviado nuestra atención hacia el plano de las preocupaciones del poeta. El pasaje en que alude a su renuncia momentánea a la poesía épica para continuar todavía con la pastoril es generalmente entendido y aceptado como el fruto de una decisión personal. La intervención divina suele quedar al margen o ser interpretada como un recurso del tipo deus ex machina, o como mera interpolación simbólica sin vinculaciones ni consecuencias con el resto del decurso significativo de la sexta. Esta línea de análisis termina por descuajar el mundo poético de Virgilio de su raíz entrañable, reduciendo sin remedio la estructura de sus obras a una serie de fragmentos incoordinados; en ellos, los dioses son parte de un repertorio útil a la historia de la mitología y a la comprobación del grado de conocimiento, precisión y profundidad con que el poeta la distribuyó adecuadamente en cada momento de su creación. Esa asamblea del Olimpo, que ningún valor ni significado tiene para nosotros, termina por no tenerlo y ser insensiblemente desechada como relevante para nuestros juicios sobre una obra y una ideología consustanciadas con la inseparable e intergiversable unidad y totalidad espirituales de un mundo: el greco-romano.

Al examinar con minucioso cuidado la secuencia presentada en la introducción de la sexta, aparece un detalle al que no le hemos asignado sino escasa importancia: Apolo se dirige al poeta, ocupado en cantar reges et proelia, para recordarle que todavía es pastor y advertirle cuál es el arte pertinente a su condición. La breve intervención divina logra disuadirlo de sus intentos épicos. Recorrer, aun con mínima atención, el 
pensamiento que Virigilio ha desarrollado a lo largo de sus tres creaciones implica percibir - o por lo menos sospechar - la presencia notable de una atmósfera peculiar, producto de una síntesis entre realidades en apariencia distantes. La idiosincrasia de Virgilio presupone una dimensión comprensiva de las diversas singularidades que conforman un universo jerarquizado en todos y cada uno de sus componentes. Ejemplo sobresaliente de esta concepción es la relación de Mopso con Menalcas (tu maior; tibi me est aequum parere, Menalca, B. V 4), y la relación de los diferentes niveles de una naturaleza que preanuncia y concuerda, desde su propio ordenamiento interno, con una gradación e índole cualitativa en la integración humana ${ }^{20}$. El concepto de orden se establece sobre la base de una jerarquía en consonancia con la justicia, donde dioses y hombres encuentran la medida necesaria y el motivo aglutinante del vínculo tensional que los religa ${ }^{21}$.

En las diez bucólicas se verifican tales principios; sus ángulos, facetas $o$ aristas, son cimientos de cada pieza en particular con sus distintos episodios; la suma de esas múltiples y difundidas estructuras similares consuenan en la unidad de la obra, la tensan, sostienen y configuran. El sistema de jerarquías a partir del que Virgilio orienta el rumbo poético de sus creaciones entraña la idea sentida del paulatino descubrimiento de lo real a través de gradaciones cognitivas. Así van conjuntándose capas y pliegues -en apariencia discordantes $u$ opuestos - sujetos a un orden inteligente y justo, donde no existe divorcio ni ruptura entre el mundo de las realidades sensibles y el de las suprasensibles. Dentro del amplio espectro que abarca la bucólica VI, nos interesa insistir en la

20 Nótense, entre otros muchos ejemplos, los dos siguientes de la bucólica V:

Lenta salix quantum pallenti cedit oliuae, puniceis humilis quantum saliunca rosetis, iudicio nostro tantum tibi cedit Amyntas.

Vitis ut arboribus decori est, ut uitibus uuae, ut gregibus tauri, segetes ut pinguibus aruis, tu decus omne tuis.

Los cantos de Mopso y Menalcas se fundan también en el mismo principio.

${ }^{21}$ Al comentar el gran fresco final del canto II de las Geórgicas, eco amplificado del espíritu dominante en la bucólica IV (cuya regencia se remonta al iam redit et Virgo del verso 6), A. M. Guillemin, a propósito de la justicia y su influjo como eje alrededor del cual se organiza el cosmos, comenta: «Pues lo debido respecto de Dios es la adoración, respecto de los padres es el reconocimiento y el amor, respecto de los amigos los servicios, respecto de los clientes la protección, etc. Extendiéndose así progresivamente, termina por abarcar todas las virtudes y constituir el factor esencial de la vida social. Desde este ángulo la encara Cicerón en el Tratado de los Deberes» (op. cit., p. 132). 
profundización de un aspecto que, silenciosa y largamente preparado, encuentra un sesgo definitivo. Las referencias, evocaciones, insinuaciones y reiteradas aproximaciones, nos han ido habituando - en particular, después de la revelación oracular de la cuarta, que ha de cumplirse en un futuro próximo ${ }^{22}$ y de la apertura lograda en el presente por la potencia transfiguradora del canto ${ }^{23}$ - a situar en un plano de natural contigüidad la vida de dioses y hombres. La irrupción de Apolo, recomendándole a Títiro dedicarse a un trabajo adecuado a su condición de pastor, ha sido presentada con tal espontaneidad que, insensiblemente, se nos pasa inadvertida la superación de la distancia entre planos tan lejanos. Con simultáneo y colateral desapercibimiento accedemos a un espacio y a un tiempo de restauración en el que dioses y hombres convergen. No se trata de una ilusión buscada con artificiosos recursos, sino de una realidad sentida como verdadera y cierta. Por ello, el poeta no ha desarrollado un cuadro anticipatorio de la aparición de Apolo en escena, apelando a palabras, giros, imágenes, o cualquier otro tipo de prólogos; por el contrario, su entrada no requiere sino de una escueta introducción, común al resto de los personajes. Es su alta condición de maestro del canto y de la revelación la que lo destaca y distingue.

En esa unidad del mundo, lograda gracias a la reinaguración de la convivencia entre dioses y hombres, se inserta la breve alocución de Apolo a Títiro:

Pastorem, Tityre, pinguis

pascere oportet ouis, deductum dicere carmen (B. VI 4-5).

El pastor ha olvidado algo y el dios, con gesto familiar, se lo recuerda. El episodio incluye dos momentos de la actitud de Apolo: un contacto fisico (aurem uellit), destinado a despertar la memoria ${ }^{24}$, y la asunción del papel de «monitor». Sus palabras tienden a hacerle recordar el sentido del oficio pastoril, aluden a la naturaleza del canto correspondiente y, metafóricamente, refieren la intima y entrañable relación existente entre el orden del mundo y la función adecuada del trabajo humano. Apolo ha acudido a censurar la transgresión implícita en la nueva actividad de Títiro (que ha de acarrear como consecuencia el desequilibrio de sus facultades perceptivas), desviado en su atención hacia un género distinto del que sabe cantar y con el que se identifica, e

${ }^{22}$ Cf. B. IV 15-16: Ille deum uitam accipiet diuisque uidebit / permixtos heroas et ipse uidebitur illis.

${ }^{23}$ Cf. B. V 56-57: Candidus insuetum miratur timen Olympi / sub pedibusque uidet nubes et sidera Daphnis.

24 Plinio, XI 251: est in aure ima memoriae locus, quam tangentes antestamur. 
intenta preservar la armonía sobre la que reposa el universo con una evocación de la importancia y valor del trabajo, como apropiada y conveniente herramienta para mantener una justa y duradera concordia. El trabajo del pastor consiste también en cantar un canto bucólico, acorde con su oficio, afinado (deductum) según el arte del que elabora la materia para extraer de ella su escondida forma. El trabajo sobre la hebra, grosera al principio, la torna suave y delicada; del mismo modo, su canto se tornará carmen una vez que sus palabras, su ritmo y su voz hayan sido afinados por un esfuerzo paciente y laborioso. En ese tránsito de perfeccionamiento que sufre el canto se verifica la transformación espiritual de quien, trabajando sobre él, ha trabajado sobre sí mismo. Reyes y combates requieren de una preparación acendrada, de una ejercitación todavía más amplia y profunda en el ámbito pastoril (sin mencionar el de la iustissima tellus), quizá porque en la culminación de la épica se alcanza, según el pensamiento de Virgilio, el máximo grado de perfección al que puede aspirar el hombre: administrar justicia ${ }^{25}$.

El pasaje citado (vv. 3-5) no hace sino sugerir, a través de una elaborada perífrasis metalingüística, la perspectiva poética dominante en la bucólica VI, en particular, y el espíritu que anima el arte compositivo todo de Virigilio. Su concepción abreva en la fuente de la tradición, desde donde mana el flujo incesante y permanente de una realidad no ordinaria, y por la que se remonta hasta los origenes metafisicos del ser en su relación con el cuerpo vivo del universo. Estrecho contacto guardan todos y cada uno de los miembros de esta dimensión cósmica, integrados en una corriente simpática que los afecta por igual. Su preservación, el sentido de su existencia y trascendencia, reside en el valor subyacente del trabajo, labor improbus, "condición imprescindible para que algo originariamente gratuito se colme a ú n más de gracia». ${ }^{26}$

Paulatina y lentamente, durante el transcurso de la bucólica VI comienzan a sucederse los variados estratos de un canto cosmogónico, un canto que se retrotrae al momento principal de la creación. El motivo dialéctico de la narracción poética acompaña y coincide con el motivo central del canto. No se desarrolla hacia el futuro, sino hacia un remoto pasado sin tiempo donde se recupera la unidad indisoluble del mundo que está siendo, tensado por su propia otredad. Los versos de la introducción, en que Apolo se dirige a Títiro, encuentran su plena justificación y culminación recurrente al entroncar con el cierre de la bucólica.

${ }^{25} \mathrm{Cf}$. Eneida VI 851: tu regere imperio populos, Romane, memento / (hae tibi erunt artes), pacisque imponere morem / parcere subiectis et debellare superbos.

${ }_{26}$ T. Haecker, Virgilio, padre de Occidente, Buenos Aires 1979, p. 76. 
Desde alli, desde ese instante en apariencia final, se desanda el camino hacia el inicio del canto, y así cíclica y eternamente. La coda de la sexta descubre al autor y ejecutante pastoril del canto:

Omnia quae Phoebo quondam meditante beatus audiit Eurotas iussitque ediscere lauros, ille canit - pulsae referunt ad sidera ualles- (vv. 82-84).

No cabe duda de que el adjetivo omnia tiene valor recapitulativo y conclusivo. En él se resumen los diversos episodios del ejercicio musical de Apolo (meditante) retomado por Títiro (meditabor), quien lo objetiva transfiriéndolo a la persona de Sileno (namque canebat...). Los versos finales de la sexta están señalando que la totalidad del canto escuchado y atribuido a Sileno no es sino el ejercicio musical que Apolo realizó en un pasado inmemorial (quondam). Los laureles lo recogieron, a instancias del ardiente deseo del río Eurotas, plenificado por el canto.

G. Williams, además de destacar la sintesis implícita en el adjetivo omnia, subraya el carácter infrecuente e incluso trágico de los relatos de amor contenidos en el canto de Sileno, y observa, con fina agudeza, que del epilogo se hace evidente que tales temas son cantados por Apolo después de la conclusión, también trágica, de su amor por Jacinto ${ }^{27}$.

E. Paratore realiza una comparación de los versos finales de la sexta con la conclusión del episodio de Orfeo en las Geórgicas, señalando una analogía estrecha entre ambos pasajes. Según el estudioso italiano, en la

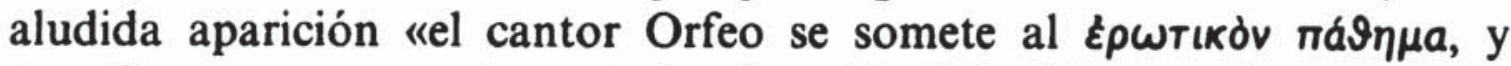
transfigura en pureza de canto la vibración del máঐos que ha trastornado su vida"; del mismo modo Apolo, que, luego de experimentar los efectos de la pasión amorosa, los ha vencido y transfigurado en canto ${ }^{28}$. Son exactas las analogías citadas por Paratore. Tanto Apolo como Orfeo han sido alcanzados por un amor que concluye de manera desafortunada. En ambos casos la actitud asumida desemboca en la muerte de la persona amada; en ambos casos el dolor se expresa y transfigura en canto, Apolo tornando beatum al río Eurotas, que escucha la melodía divina, moviendo con su entusiasmo a los laureles -árboles consagrados al dios - a aprenderla de memoria; Orfeo, encantando con su lamento a los tigres y conduciendo las encinas ${ }^{29}$. Paratore

${ }^{27}$ G. Williams, Tratition and Originality in Roman Poetry, Oxford 1968, p. 246. Con respecto al amor de Apolo por Jacinto y la relación de ambos con el Eurotas, conviene recordar la cita del llamado Seruius auctus; al referirse al río mencionado en el verso 83, explica: nam hunc fluuium Hyacinthi causa Apollo dicitur amasse.

${ }^{28}$ E. Paratore (n. 15), pp. 510-511.

${ }^{29}$ Cf. Geórgicas IV 510: mulcentem tigris et agentem carmine quercus. 
llega, incluso, más lejos: destaca el uso del mismo verbo para describir el sonido del eco que lleva (referunt) desde los valles hasta los astros el canto de Sileno, así como en el episodio geórgico de las riberas del Hebro hacían resonar (referebant) el nombre de Eurídice, de quien, ausente, sólo queda el suspiro por Orfeo ${ }^{30}$. Ambos pasajes concuerdan, en líneas generales, en sus motivaciones y desarrollo, pero divergen en su atmósfera y resultado finales. El canto de la bucólica VI plenifica y despierta el entusiasmo de quienes lo escuchan; en cambio, las riberas del río repercuten, en la cuarta geórgica, con un canto y una voz de profunda aflicción.

La relación entre Apolo y Sileno ha motivado la preocupación y el esfuerzo de esclarecimiento de J. Perret. Según el estudioso, que se apoya sobre dos grupos de textos antiguos, Sileno habita en Laconia, al sur de cuya región había nacido (en Málea, promontorio del Peloponeso). A esto se suma que, de acuerdo con una antigua tradición, Apolo arcadiano, el dios en su carácter bucólico, es hijo de Sileno. Partiendo de tales informaciones Perret llega a la conclusión de que la escena descrita en los versos finales de la sexta - en que Apolo se encuentra cantando a orillas del Eurotas - no debió sorprender la sensibilidad de los contemporáneos de Virgilio, conocedores de la peculiar geografia cuyo registro confirma el comentario atribuido a Probo: Eurotas... fontes agit ex monte Maenalio, el Eurotas nace en Arcadia, donde se sitúa el monte Ménalo ${ }^{31}$. La relación entre los arcadios Apolo y Sileno parece suficientemente esclarecida.

Una perspectiva distinta sobre el epílogo de la sexta se debe a G. Lieberg. Según su apreciación, Virgilio es depositario de una larga tradición sobre la teoría de la armonía de las esferas presidida por Apolo, que, reelaborada y refundida con aportes de fuentes diversas, hace sentir su influjo en varios pasajes de sus tres obras. Tomando como punto de referencia un texto de Varrón de Átax, comienza a hilar los diferentes elementos que han sido transferidos a los versos finales de la bucólica y, acudiendo a otras vertientes, explica las modificaciones realizadas por Virgilio con respecto a la mencionada teoria. El estudio de Lieberg intenta finalmente resolver un problema capital: para que la interpretación del epílogo de la sexta bucólica no ofrezca dudas, se debe tener la seguridad de que Virgilio conocía el papel atribuido a Apolo con respecto a la armonía celeste por los textos presentados ${ }^{32}$. Apoyán-

\footnotetext{
${ }^{30}$ Cf. Geórgicas IV 527: Eurydicen toto referebant flumine ripae.

${ }^{31}$ J. Perret, Sileni Theologia: Vergiliana. Recherches sur Virgile, Leiden 1971, pp. 301-305.

${ }^{32}$ G. Lieberg, "L'harmonie des sphères chez Virgile?», p. 355.
} 
dose en un episodio de las Geórgicas responde afirmativamente. El conjunto de sus indagaciones le permite concluir que Virgilio conoció y valoró la figura de Apolo como fuerza primera del universo, como esencia originaria y reguladora de la armonía de las esferas: «Virgile, dans l'épilogue de la sixième Églogue a été fortement influencé par la conception de l'harmonie des sphères presidée par Apollon. Naturellement, il ne la reproduit pas par une imitation servile. Il la transforme dans l'esprit du monde bucolique, en faisant rechanter aux astres cette mélodie qui arrive jusqu'à eux à travers les espaces cosmiques et la nature sensible, de la voix d'Apollon qui transfigure en accents mélodieux son amour tragique pour Hyacinthe.» ${ }^{33}$

Según nuestro entender, los precedentes constituyen los juicios contemporáneos más relevantes - herederos de una larga tradición crítica a la que enriquecen y sintetizan - sobre la presencia de Apolo en el epílogo de la sexta bucólica. En lo concerniente al conjunto del pasaje, consideramos que será suficiente acudir a dos contribuciones precisas y certeras. Con distinta sensibilidad ambos críticos han intentado describir la unidad lograda entre la atmósfera sobrenatural de la realidad poética y el acotado contexto de la realidad ordinaria. Sus respectivas reflexiones, en apariencia distantes, se complementan.

Marie Desport exalta el encanto crepuscular y sideral del pasaje, resaltando el deseo de los dioses que no se resignan a dejar de escuchar el canto principal de Apolo (en cuyo eco se funden cielo y tierra), mensajero de rumores resonantes sobre el manto de la suspendida incertidumbre sideral ${ }^{34}$. Desport alude finamente al poderío de la palabra poética, reveladora por proferición, a lo largo de una obra sutil y plena de significativas sugerencias.

Eleanor W. Leach señala la amplitud de sentido del mundo instaurado en el epílogo de la bucólica, debido a la fusión entre mito y naturaleza: «But the conclusion of the poem ironically brings back the limitations of the natural world. As the river Eurotas had once cherished the words of Apollo, so do the gods on Olympus wish for the continuation of the Silenus Song. There is no return to the limited literary world of pastoral seen at the beginning of the poem; instead pastoral, myth and nature blend into one larger world which is both the landscape and substance of the Silenus Song.") ${ }^{35}$ Para Leach el mundo de la naturaleza, representado por Véspero con su movimiento regular, implica la úl-

${ }^{33}$ Ibidem, p. 357.

${ }^{34} \mathrm{M}$. Desport, L'incantation virgilienne. Essai sur les mythes du poète enchanteur et leur influence dans l'oeuvre de Virgile, Burdeos 1952, p. 171.

${ }^{35}$ E. W. Leach, "The Unity of Eclogue 6", Latomus 27, 1968, p. 31. 
tima palabra, el límite al que se sujeta el mundo literario, propio del arte. La identidad del mundo natural, de la realidad ordinaria, reaparece al final imponiendo sus reglas. Si bien, en gran medida, es cierto lo afirmado por Leach, creemos que la hondura significativa de la disociación verificada en la coda de la sexta se abre, más que al antagonismo de dos dimensiones semovientes e independientes entre sí, a un contexto de interpretación en el que el canto (carmen), gracias a su potencia asuntiva, cumple la función de reincorporar y reconducir las múltiples ramificaciones de la realidad hacia su sentido principal de unidad e integridad. El mundo natural adquiere su identidad por carencia, una vez que el carmen ha cesado. A partir de ese momento se diferencia, retorna a su rutina (donec marca la línea divisoria que indica el alejamiento de una realidad no ordinaria y el reingreso en la de las preocupaciones humanas que acaecen con regularidad: cogere ouis stabulis numerumque referre). En ese momento de transición, poblado todavía con los ecos del canto apolíneo, Véspero, sidus Veneris ${ }^{36}$, reinicia su marcha, rodeado de una atmósfera fuertemente sensibilizada. La suspensión del canto la sumerge en el sinfin de la experiencia cotidiana; contra esa regresión reacciona con disgusto (inuito Olympo). En el contraste de su actitud resalta con claridad su filiación original.

La unidad manifiesta de los niveles más dispares del universo, concentrada en el epílogo de la sexta bucólica, evidencia uno de los aspectos fundamentales que confieren cohesión a la pieza y completan la perspectiva inicial de Virgilio sobre su concepción artística, coronándola con una conclusión recapitulativa: «c'est ainsi que l'Églogue se termine sur une note profondement bucolique, note qui renvoie au prologue de la pièce où Apollon s'adresse, même si c'est dans un sens métaphorique, au poète-berger Virgile en l'exhortant à faire paître des brebis grasses et où celui-ci, obéissant à l'avertissement divin, s'apprête à chanter sa Muse champêtre». ${ }^{37}$

Así como el adjetivo omnia nos devuelve desde el final de la sexta a la reconsideración de cada uno de los pasajes del canto de Sileno, el particular desvelamiento del origen de tal canto - un ejercicio musical de Apolo, suficiente para crear un carmen que hechiza y arroba a dioses y hombres-, y el cese del mismo, con su inmediata consecuencia: el retorno de la realidad ordinaria, nos empujan a rememorar y redescubrir la estructura compositiva de la bucólica. El encuentro de estos dos ejes se produce en un punto crucial que atañe al espíritu de Virgilio y a su

${ }^{36}$ Cf. Plinio el Viejo, $H$. N. II 36.

${ }^{37}$ G. Lieberg (n. 32), p. 357. 
concepción acerca del arte, un arte que conserva y recrea la dimensión primigenia, el logos del cosmos, entreabierto por el canto desde la inercia de las pasiones humanas, desde el reino clauso del despojo y la pérdida cotidianos (usque adeo turbatur agris, B. I 12). Escala tendida al secreto trasfondo de toda realidad (donde conciertan las identidades del hombre y del mundo), la meditatio quondam Phoebea despliega un canto auroral que fluye desde la multiplicidad hacia la unidad primera, desde el presente del pastor Títiro - que recupera el momento principial en el pasado miliar de Sileno, reintegrándose a un holon pleno de sentido, donde la historia encuentra su espacio y razón-, hasta el nacimiento ab integro del gran orden. En omnia laten todos los episodios, todo el futuro ya acaecido durante el decurso del canto apolíneo. El epílogo de la bucólica reasume en nueva e indivisible densidad la varia y dispar complejidad del universo. Su mostración (sean cuales fueren sus más disímiles niveles, no obstante estén todos ellos insumidos en una estructura organizada y consonante) adviene por medio de la vía lírica. La coda de la sexta marca no sólo la culminación hacia la que fluyen todos sus particulares segmentos; también se tiene la sensación de haber arribado a un pináculo no ordinario desde el que se contempla la heterogénea conformación de un mundo, un templum. El recurso no es nuevo: Cicerón había cerrado su de re publica con aquel Somnium Scipionis de tan buena fortuna en la literatura cristiana posterior, donde el Africano contemplaba asombrado un templum cósmico-histórico a través de la revelación de su abuelo. Lucrecio había adelantado la imagen, de similar concepción, con sus templa serena. Pero en Virgilio percibimos una diferencia esencial: la contemplatio descrita por sus predecesores ha dejado de ser una teoría para volverse una entidad real; esa operación estética es posible gracias a la fuerza transfiguradora del canto, por el que reaparece la recóndita forma de las cosas. La bucólica VI progresa desde un presente próximo pero indefinido hacia un pasado remotísimo pero siempre actual, hacia una fuente donde cohabitan los más disimiles niveles del universo, modulados por el impulso transfigurador de la lengua original, la palabra poética (Phoebo quondam meditante), de cuyo eco último es depositario el pastor (agrestem tenui meditabor harundine musam), eslabón y punto de confluencia del ritmo natural de lo existente y del sobrenatural de lo latente (pastorem, Tityre, pinguis / pascere oportet ouis, deductum dicere carmen) como fuerzas complementarias de un mismo y único orden. No hay exclusiones en la amplísima y envolvente onda musical que describe la bucólica sexta, no las hay tampoco en la compleja arquitectura del monobiblos, temperada de diez cantos inalineables según los cánones del racionalismo mo- 
derno. La libertad selectiva de Virgilio y su capacidad espiritual para contemplar, aprehender y expresar la totalidad de la naturaleza desborda el ámbito de las corrientes literarias y de las fáciles definiciones críti-

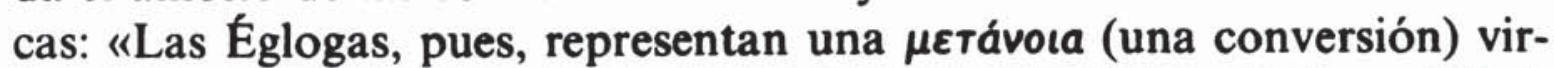
giliana, en la manera de entender la significación última de la realidad. Ésta es ahora, en sus elementos concretos, el principio de una transfiguración. Pero el poeta no contrapone realidad e idealidad; no enfrenta lo cotidiano y lo sacro, el orden cósmico y el orden humano, etcétera, sino que funda un vínculo: el 'canto' de los pastores ha descubierto el rostro venidero de las cosas, el rostro que está oculto en la aparente caducidad de sus rasgos.» ${ }^{38}$

El epílogo de la bucólica sexta recapitula, cierra y unifica al mismo tiempo los distintos segmentos de su estructura poética, traspasando los límites iniciales del relato para progresar, en el espacio propicio del antro de Sileno, hasta la reposición instantánea y fugaz, pero reveladora, del mito, donde se anula la sucesión indiscriminada e incesante del devenir histórico y se renueva la integridad múltiple y principal del ser. El planteamiento de Virgilio no es teórico, sino conceptual. Su arte, orientado en la idea de continuidad de la tradición y, por consiguiente, en la voluntad de legar, asigna una especial valoración al ejercicio del oficio, instrumento eficaz para recibir el conocimiento y reconocer las propias potencialidades. El presupuesto de la razón, como fuerza autosuficiente para penetrar con su propio orden en un orden de naturaleza no racional, no sólo naufraga en el profundo antro de las realidades no visibles sino que se derrumba desde sus cimientos ante la imposibilidad de reducir un pensamiento poético a contenidos lógicos, una expresión sintética a una analítica. La aceptación de la particularidad instransferible incluye la estabilidad colectiva de los distintos niveles del universo, en tanto justicia de lo conveniente, en tanto decus de plural igualdad, en tanto plena concordancia de un organismo armónico. Omnia recapitula el canto de Sileno, ejercicio musical realizado por Apolo en un tiempo remoto a orillas del Eurotas; éste, a su vez, plenificado por la magnitud del canto, deseó ardientemente que lo aprendieran de memoria los laureles - cuya divinidad tutelar es el mismo Apolo-; el canto se difunde por la naturaleza, la traspasa de lado a lado y, cual flecha lanzada por un cósmico arco, la pulsa con vibraciones que se elevan hasta los astros. El adelantamiento de Véspero parece alzarse como el signo dinámico que señala la suspensión del canto y el retorno a la rutina cotidia-

${ }^{38}$ C. Disandro, "Virgilio y su mundo poético", en Semanas de Estudios Romanos, Universidad Católica de Valparaíso, 1977, vol. I, p. 56. 
na; el disgusto alude a la discontinuidad producida por la ruptura entre la realidad ordinaria y la contenida en la creación apolínea. La ruptura adviene al cesar el canto; consecuentemente se percibe la pérdida de uno de los miembros con que se completa la realidad toda.

El epílogo de la bucólica sexta retrotrae la estructura poética a una culminación de sentido cuya primera manifestación se encuentra en las palabras de Apolo a Títiro, recordándole la función que, como pastor, debe asumir y ejercer. En la aceptación de ese llamado redescubre el canto inspirado (non iniussa cano) donde vibra y se reconoce la naturaleza de las cosas, donde se desliga gradualmente del decurso temporal de la historia para sumergirse en un tiempo vivo, en un presente fijo del Principio que contiene todos los principios y donde todo principia en todos los instantes.

La concepción artística de Virgilio no puede reducirse a simples fórmulas, pues no se ajusta a lineamientos de fácil definición. Su imaginación no es arbitraria $y$, por consiguiente, no inventa las formas de las cosas. Antes bien, prefiere mostrarlas en su dimensión más acendrada, haciéndolas visibles y nuevamente cognoscibles gracias a la fuerza iluminante del mito que opera en su expresión poética. Ese mundo mítico, tendido y tensionado por su palabra poética, no puede, a su vez, ser abordado si se intenta penetrar en él con una actitud puramente teórica o meramente práctica; su estructura es simpatética, y sólo una exploración de la misma naturaleza logra ingresar en su complejo ordenamiento. Así, en la fecundísima poesía del ámbito bucólico la informe dispersión de lo cotidiano se torna coherencia armoniosa. En la aluvional, aparentemente caótica y carente de sentido, diversificación de honduras intelectivas y comprensivas que propone la bucólica sexta, se encierra la variedad y unidad infinitas del mundo y del hombre, celebrados en el canto que los recrea.

RUBEN FLORIO 